\title{
Study of factors affecting contraceptive use among married women of reproductive Age
}

\section{N. Bhandari , ${ }^{1}$ G.K. Shrestha, ${ }^{2}$ P C Thakuri ${ }^{3}$}

${ }^{1}$ Assistant Professor, ${ }^{2}$ Associate Professor, Kathmandu University School Of Medical Sciences

${ }^{3}$ Nursing Instructor,Bharatpur Medical College

\section{ABSTRACT}

\section{Background}

The use of contraception can prevent pregnancies related complication and helps in improving the women's health and quality of their lives.

\section{Objective}

To explore reproductive characteristics among married women of reproductive age.

To find out method of contraceptive use and side effects among married women of reproductive age.

To uncover factors related to contraceptive use among married women of reproductive age.

\section{Methods}

This cross-sectional was carried out among (369) married couples of reproductive age group in ward number 5, 6 and 7 of Dhulikhel Municipality using purposive sampling. Those who fell in between the age group of (14-49 years) and willing to participate were included and pregnant women were excluded from the study. Questionnaire was used to obtain informations.

\section{Results}

Among 369(81.3\%) of the respondents of reproductive age were using a modern contraceptive method. Regarding education 331(89.5\%) of women's and 352(95.1\%) of husbands were literate and 275(91.6\%) of women were found to be involved in decision making and had good inter-spousal communication that is $280(93.3 \%)$. Among the temporary method of family planning, Depo-Provera was the choice 150(54.5\%) of contraceptive method.

\section{Conclusion}

The present study put more emphasis on increase in women's literacy, women's involvement in decision making and inter-spousal communication which helps to promote the effective use of contraceptive methods. As women play an important role in the decision making, women should be included in all aspects of reproductive health and family planning programs.

Key words: Contraceptive prevalence rate, contraceptive use, married couple.

Correspondence: N. Bhandari

E-mail: neemakusms@yahoo.com 
Journal of College of Medical Sciences-Nepal, 2013, Vol-9, No-4,

\section{INTRODUCTION}

Family planning is now an integral part of the health system of Nepal. Despite political instability and armed conflict in the last decade, Nepal has made remarkable progress in the use of modern contraceptives methods, especially during the period between 1996 and 2006. ${ }^{1}$ Nepal has received international awards for improving its maternal and child health status. ${ }^{2}$ Family planning (FP) is a priority programme of the Ministry of Health and Population (MOHP) and a component of the reproductive health package and essential health care services of the Nepal Health Sector Program II (2010-2015) Besides the number of indicators to measure the progress of the family planning programme, however, the MOHP has selected three indicators; total fertility rate (TFR), adolescent fertility rate (AFR), and CPR as a part of the Millennium Development Goals (MDGs). ${ }^{3}$ The main objectives of the Family Planning Programme are to assist individuals and couples to: space and/or limit their children. Prevent unwanted pregnancies, improve their overall reproductive health. ${ }^{4}$ Family planning is one of the major components of Reproductive Health Programme. Contraception methods like Depoprovera, pills and Condoms are available nationwide upto sub health post level. So, researcher attempt with the objectives to: explore reproductive characteristics among married women of reproductive age, to find out method of contraceptive use and side effects among married women of reproductive age and to uncover factors related to contraceptive use among married women of reproductive age to conduct research.

\section{METHODS}

This is a quantitative cross-sectional study design conducted among all married couples of reproductive age group (14-49 years) using purposive sampling procedure The study was conducted in Dhulikhel Municipality ward no. 5, 6 and 7. Ethical approval was taken from (IRCKUSMS) and verbal consent was taken from the respondents and assured regarding anonymity, confidentiality and privacy of information received from them. The desire of the respondents were highly appreciated and were not forced to take part in the study. Questionnaire was used to obtain information from the respondents. The outcome of the study was measured in terms of descriptive statistics such as frequency and percentage. For the purpose SPSS 16.00 was used.

\section{RESULTS}

In order to determine the factors affecting contraceptive use among married couples of reproductive age group, the univariate analysis was done. 
Study of Factors Affecting Contraceptive use among Married Women.

Table 1: Socio- demographic and reproductive characteristics $(N=369)$

\begin{tabular}{lll}
\hline Variables & Total f $(\boldsymbol{\%})$ & \\
\hline Age of women & \multicolumn{2}{l}{} \\
\hline & $21-35$ & $35(9.4)$ \\
& $36-49$ & $230(62.3)$ \\
Women's education & & $104(28.1)$ \\
& Illiterate & $38(10.2)$ \\
Husband's education & Literate & $331(89.5)$ \\
& & $17(4.6)$ \\
Total number of living children & Illiterate & $352(95.4)$ \\
& Literate & $325(88.0)$ \\
& One & $44(11.9)$
\end{tabular}

A total of 369 respondents were registered in the present study. Their mean age was $24.7 \pm 4.3$ years, with a maximum of 40 and a minimum of 18 years; 230(62.3) of respondents aged 21-35 years. Among the respondents 331(89.5) of women were literate. The respondents using temporary method of family planning were having one child found $325(88)$ and the reasons for adopting were either for postponing or for spacing the next. The respondents having two or more children 44(11.9) were adopting permanent method of family planning.

Table 2: Contraceptive use, method and side effects ( $\mathrm{N}=300$ )

\section{Variables}

Total f (\%)

Contraceptive use

Yes

$300(81.3)$

No

69 (18.6)

Contraceptive methods used

Experience side-effect

$\begin{array}{lc}\text { Permanent } & 25(8.3) \\ \text { Temporary } & 275(91.6)\end{array}$

Yes

63 (22. 9)

The respondents who were using contraception were 300(81.3) of which 275(91.6) were using the temporary method of family planning and among which the most commonly used was DepoProvera 150(54.5). Among the contraceptive users 63(22.9) found to have side-effects of irregular menstruation 16 (25.3) was the most common side-effect. 
Table 3: Factors related to contraceptive use ( $N=369)$

\begin{tabular}{|cccc}
\hline $\begin{array}{c}\text { Variables } \\
\text { Duration of marriage (years) }\end{array}$ & User (300) & Non-User (69) & Total (369) \\
Less than 10 years & $149(49.6)$ & $50(72.4)$ & $199(53.9)$ \\
10 and above years & $15(50.3)$ & $19(27.5)$ & $170(46.0)$ \\
Desire for additional children & & & \\
Want more & $22(7.3)$ & $15(21.7)$ & $37(10.0)$ \\
Want no more & $278(92.6)$ & $54(78.2)$ & $332(89.9)$ \\
Sex preference of the child & & & \\
Yes & $95(31.6)$ & $19(27.5)$ & $114(30.8)$ \\
No & $205(68.3)$ & $50(72.4)$ & $255(69.1)$ \\
Decision & & & \\
Women involved & $275(91.6)$ & $40(57.9)$ & $315(85.3)$ \\
Women not involved & $25(8.3)$ & $29(42.0)$ & $54(14.6)$ \\
Inter-spousal communication & & & \\
Discussed & $280(93.3)$ & $51(73.9)$ & $331(89.7)$ \\
Never discussed & $20(6.6)$ & $18(26.0)$ & $38(10.2)$ \\
\end{tabular}

Among the respondents 149(49.6) of couples were married 10 or above years. Seven percentages of couples want additional children because either they had one child or desire for different sex. Among the couples 95(31.6) had sex preference. Respondents involved in decision making 275(91.6) were using contraception, involvement of Respondents in decision making found to have promoted the use of contraception. Good inter -spousal communication 280(93.3) also promote the use of contraception.

\section{DISCUSSION}

Good reproductive health depends largely on how well people are informed on contraception issues. In present study 300(81.3) of the respondents were using a modern contraceptive method. In 2008 in Nepal based on data from the NDHS 2001 and 2006 revealed that current use of contraception among married women increased from 39\% in 2001 to $48 \%$ in $2006 .{ }^{5}$ In contrast only $31 \%$ of respondent were using modern contraception in Cambodia. ${ }^{6}$ Among the respondents 230(62.3) of women which respondents of age 21-35 years among the user and 35(9.4) of women were below and equal to 20 years. Chourn 2008 concludes that contraception use was highest in the age group of 35-39 (17.6). ${ }^{6}$ This may be the reason in advanced age maturity arises. In other study in Nepal discussed that there is $35 \%$ increase in the family planning methods among women with no education .$^{5}$ One of the studies done in Nepal showed contrast result that use of contraceptive was highest among couples in which the women had no education and her husband had some secondary or higher education 58\%. Women with primary, secondary and higher level of education are more likely to use modern contraception than those with no education.$^{6}$ Husbands with any secondary or higher education were the most likely to use male 
Study of Factors Affecting Contraceptive use among Married Women.

sterilization (8\%). ${ }^{7}$ About $90 \%$ of the married adolescents who were not using contraception had no education compared to $89.5 \%$ of adolescents with education. ${ }^{\mathbf{8}}$

In study it is concluded that a total of $56.1 \%$ of illiterate women had used contraceptive methods, while for others who had received primary, secondary, diploma and higher education this rate was $59.5 \%, 60.8 \%, 63.3 \%$ and $69.7 \%$ respectively. ${ }^{9}$ Husband's literacy was $96.5 \%$ similarly; in one study concluded that contraceptive use of women with more educated husbands was higher than for those with less educated husbands.$^{8}$ Husband's education was also found to be significantly associated with the practice of family planning. ${ }^{10}$ Contraceptive use in women with more educated husbands was higher than for those with less educated $65.6 \%$ among women whose husbands had a university degree, $59.8 \%$ in those literate upto diploma and $52.9 \%$ women with illiterate husbands. ${ }^{9}$ The Depo-provera was popular method used by respondents in the present study $150(54.5)$. The factor might be method used by respondents hat many women tend to use the same family planning methods as others in their social networks. Even when people are aware of the side effect(s) or failure experienced by others users of a method, sometimes they still tend to prefer it because it is familiar to them. In this study respondents who had no side effects 306(91) were using contraceptive method more than those having side effects 63(22.9). The findings are similar to the study conducted in India which concluded that many of the respondents did not prefer any of the family planning methods due to its side effects $50 \% .^{11}$ Inter-spousal communication in the present study among the user 280(93.3\%) and 275(91.6\%) of women involved in decision making regarding contraception with their spouse. Similarly, the study conducted in Palestine that stated women who were involved in decision making regarding family planning $(55.9 \%)$ were more likely to use contraception than those not involved $(47.4 \%){ }^{12}$

\section{CONCLUSIONS}

Rapid population growth is one of the serious problems the world is facing now. In Nepal also, increasing population has been a challenge in population need fulfillment programs of the Government of Nepal. So, containment of population growth becomes urgent and contraceptive use can prevent the current problems. As it can be seen that women play an important role in the decision making, women should be included in all aspects of reproductive health and family planning programs.

\section{REFERENCES}

1. Ministry of health and population, New Era, ICF Macro, USAID. Nepal Demographic and Health Survey 2011. Kathmandu: Ministry of Health and Population; 2012

2. Nyaya Health. Nepal receives award for decreasing maternal mortality, but challenges and disparities remain. 2010. Available from: http://blog.nyayahealth.org/2010/10/04/ mdgaward/.

3. REF Government of Nepal. Nepal Health Sector Program-II (2010-2015). Nepal: Ministry of Health and Population; 2010

4. Annual Report. DoHS. 2066/67(2009/2010). Ministry of Health and Population. Department of Health Services. Kathmandu

5. Karki, YB, Krishna R. Factors responsible for the rapid decline of fertility in Nepal-An interpretation, Further Analysis of the Nepal 
Journal of College of Medical Sciences-Nepal, 2013, Vol-9, No-4,

Study of Factors Affecting Contraceptive use among Married Women.

Demographic and Health Survey. Calverton,

9. Tehrani FR, Farahani FKA, Hashemi MS.

Maryland, USA: Macro International Inc. (2006)

6. Chourn, T. (2008). Factors Influencing modern contraceptive use among currently married women in Cambodia Available from: http:// www.li.mahidol.ac.th/thesis/2551/cd419/ 5038598.pdf

7. Gubhaju, B.The influence of wives' and husbands' education levels on contraceptive method choice in

Nepal, International Perspectives on Sexual and Reproductive Health, 2009; 35(4), 1-12

8. Tamang J. Factors Related to Contraceptive Non-use and among Married female Adolescents in Nepal. An Unpublished Thesis Submitted to Faculty of Graduate Studies, Mahidol University Thailand. (2001) 